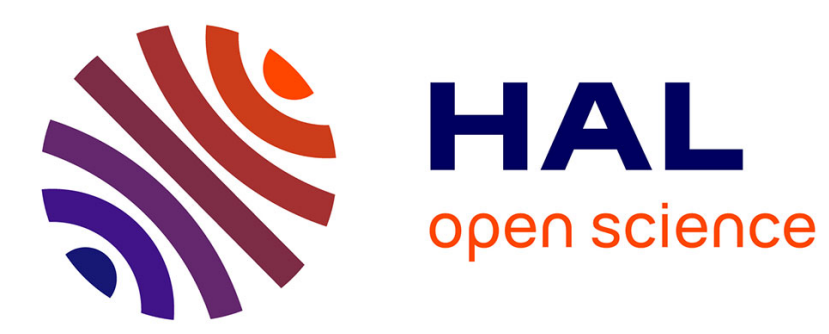

\title{
Outcomes of Drug-Based and Surgical Treatments for Primary Aldosteronism
}

Olivier Steichen, Aurelien Lorthioir, Franck Zinzindohoue, Pierre-François Plouin, Laurence Amar

\section{- To cite this version:}

Olivier Steichen, Aurelien Lorthioir, Franck Zinzindohoue, Pierre-François Plouin, Laurence Amar. Outcomes of Drug-Based and Surgical Treatments for Primary Aldosteronism. Advances in Chronic Kidney Disease, 2015, 22 (3), pp.196-203. 10.1053/j.ackd.2014.10.003 . hal-01153360

\section{HAL Id: hal-01153360 https://hal.sorbonne-universite.fr/hal-01153360}

Submitted on 19 May 2015

HAL is a multi-disciplinary open access archive for the deposit and dissemination of scientific research documents, whether they are published or not. The documents may come from teaching and research institutions in France or abroad, or from public or private research centers.
L'archive ouverte pluridisciplinaire HAL, est destinée au dépôt et à la diffusion de documents scientifiques de niveau recherche, publiés ou non, émanant des établissements d'enseignement et de recherche français ou étrangers, des laboratoires publics ou privés. 


\section{Outcomes of drug-based and surgical treatments for primary aldosteronism}

Olivier Steichen, ${ }^{1,2,3}$ Aurelien Lorthioir, ${ }^{4,5,6}$ Franck Zinzindohoue, ${ }^{6,7}$ Pierre-François Plouin, ${ }^{6,8}$ Laurence Amar ${ }^{6,8}$

${ }^{1}$ Assistance Publique-Hôpitaux de Paris, Hôpital Tenon, Department of Internal Medicine, Paris, F-75020, France;

${ }^{2}$ Sorbonne Universités, UPMC Univ Paris 06, Faculty of Medicine, F-75013, Paris, France;

${ }^{3}$ Inserm, UMR_S1142, LIMICS, F-75005, Paris, France;

${ }^{4}$ Assistance Publique-Hôpitaux de Paris, Hôpital Européen Georges Pompidou, Clinical Investigation Centre 9201, Paris, F-75015, France;

${ }^{5}$ Inserm, Clinical Investigation Centre 9201, Paris, F-75015, France;

${ }^{6}$ Université Paris-Descartes, Faculty of Medicine, Paris, F-75006, France;

${ }^{7}$ Assistance Publique-Hôpitaux de Paris, Hôpital Européen Georges Pompidou, Department of Visceral Surgery, Paris, Paris, F-75015, France;

${ }^{8}$ Assistance Publique-Hôpitaux de Paris, Hôpital Européen Georges Pompidou, Hypertension Unit, Paris, Paris, F-75015, France.

Primary and corresponding author: Olivier Steichen

Service de médecine interne, hôpital Tenon

4 rue de la Chine, 75020 Paris, France

Tel +331560178 31; Fax +33156017082

E-mail: olivier.steichen@tnn.aphp.fr

Financial disclosure: The authors have no financial disclosures to make or conflicts of interest to declare. 


\section{Abstract}

Treatments for primary aldosteronism (PA) aim to correct or prevent the deleterious consequences of hyperaldosteronism: hypertension, hypokalemia and direct target organ damage. Patients with unilateral PA considered fit for surgery can undergo laparoscopic adrenalectomy, which significantly decreases blood pressure and medications in most cases, and cures hypertension in about $40 \%$. Mineralocorticoid receptor antagonists (MRA) are used to treat patients with bilateral PA and those with unilateral PA if surgery is not possible or not desired. Spironolactone is more potent than eplerenone, but high doses are poorly tolerated in men. MRA can be replaced or complemented with epithelial sodium channel blockers, such as amiloride. Thiazide diuretics and calcium channel blockers are used when the first-line drugs are insufficient to control blood pressure. Dietary sodium restriction should be implemented in all cases, because the deleterious consequences of hyperaldosteronism are dependent on salt loading. Several studies comparing the results of surgery and MRA have reported no differences in terms of blood pressure, serum potassium concentration or cardiovascular and renal outcomes, although the benefits of treatment tend to be observed sooner with surgery. PA patients display relative glomerular hyperfiltration, which is reversed by specific treatment, revealing chronic kidney disease in $30 \%$ of patients. However, further kidney damage is prevented by the treatment of PA.

\section{Clinical summary}

- The goals of treatment are the normalization of serum potassium concentration, blood pressure control and prevention of the direct effects of excess aldosterone on target organs. 
- The non-surgical treatment of PA is based on mineralocorticoid receptor antagonists and dietary sodium restriction.

- Epithelial sodium channel blockers are used when mineralocorticoid receptor antagonists are not well tolerated; thiazide diuretics and calcium channel blockers are used when blood pressure control is insufficient with the first-line treatment.

- Laparoscopic adrenalectomy is safe and decreases BP and medication requirements in patients with unilateral PA; drug-based treatments are appropriate in cases in which surgery is inappropriate or not desired.

\section{Keywords}

Hyperaldosteronism; Adrenalectomy; Mineralocorticoid receptor antagonists; Epithelial sodium channel blockers; Chronic kidney disease. 


\section{Introduction}

Primary aldosteronism (PA) is the state of autonomous aldosterone overproduction by one or both adrenal glands. ${ }^{1}$ Activation of the mineralocorticoid receptor increases the number of epithelial sodium channels $(\mathrm{ENaC})$ and sodium chloride cotransporters $(\mathrm{NCC})$ on the epithelial cell membrane of distal tubules and collecting ducts. ${ }^{2}$ This leads to sodium reabsorption and potassium secretion, resulting in an increase in plasma volume and hypokalemia. However, sodium availability in the distal tubule must exceed a certain amount for these consequences to occur. Hypertension results partly from an increase in plasma volume and partly from the aldosterone-mediated vasoconstriction of systemic arteries. ${ }^{3}$ Target organ damage is mostly due to hypertension, but aldosterone also promotes oxidative stress, inflammation and fibrosis in the kidney and other organs (heart, vessels, adipose tissue). These effects are also dependent on salt loading and may be partly independent of the mineralocorticoid receptor. $^{4-6}$

Treatment aims to decrease the morbidity and mortality associated with PA and to improve the quality of life of patients. Economic constraints make it necessary to achieve these ends at the lowest possible cost. The most logical way to achieve these goals is to normalize aldosterone secretion. This is possible in patients with unilateral PA, through removal of the offending adrenal gland. Aldosterone synthase inhibitors are currently being developed but are not yet used in clinical practice.

Mineralocorticoid receptor antagonists (MRAs) counteract most, but not all the biological effects of hyperaldosteronism. However, they yield clinical results comparable to those achieved by adrenalectomy. ENaC blockers impede only some of the many pathways leading to target organ damage, but are useful adjunctive treatments, together with dietary sodium 
restriction, for controlling blood pressure (BP) and hypokalemia. Non-specific

antihypertensive agents are often required in addition to these specific treatments, to control hypertension.

We will begin by describing the principal treatments for PA — surgery and antihypertensive drugs — and reviewing their outcomes. We will then discuss the most appropriate uses of these treatments according to PA subtype, and the clinical circumstances and individual preferences of patients.

\section{Unilateral adrenalectomy}

The vast majority of adrenal lesions causing unilateral PA are small and benign, and are therefore ideal candidates for laparoscopic adrenalectomy, for which morbidity is lower and hospital stays are shorter than for open surgery. ${ }^{7,8}$ Several surgeons have advocated partial adrenalectomy as a safe and feasible way of removing single aldosterone-producing adenomas (APA). ${ }^{9,10}$ However, the benefits of this adrenal gland-sparing approach are questionable in PA, because contralateral tumors requiring subsequent adrenalectomy are very rare.

Moreover, 10 to $25 \%$ of patients with unilateral PA have multiple adjacent nodules that may be missed on preoperative adrenal imaging, and the largest lesion is not necessarily the lesion responsible for PA. ${ }^{11}$ Several percutaneous alternatives for the destruction of APAs have been proposed, including ethanol injection, arterial embolization, cryoabalation and radiofrequency ablation. ${ }^{11,12}$ These techniques are less invasive than surgery, but the long-term outcome and risks are uncertain. They should therefore be used only within the confines of a study protocol. 
Surgeons may opt for a transperitoneal or for a retroperitoneal approach. Both approaches have drawbacks and advantages. The lateral transperitoneal laparoscopic approach exposes the adrenal gland to a greater extent, whereas the retroperitoneal approach avoids facing adhesion in patients who have previously undergone intra-abdominal surgery, and potentially reduces the duration of the patient's stay in hospital. ${ }^{13}$ Laparoscopic adrenalectomy usually requires three to four ports for the introduction of the instruments, but a single-port transumbilical approach is possible. ${ }^{14,15}$ Robot-assisted laparoscopic adrenalectomy is feasible and safe but more expensive, and its advantages over conventional laparoscopy have yet to be definitively demonstrated. ${ }^{15-17}$

The mean operating time for laparoscopic adrenalectomy performed by experienced surgeons in major series is between one and two hours, and mean hospital stay is about three days. ${ }^{18,19}$ Conversion to open surgery is required in less than $5 \%$ of cases. ${ }^{8}$ Perioperative mortality is less than $0.5 \%$, non-fatal complications occur in $5 \%$ to $15 \%$ of cases and most of them are benign (temporary relaxation and/or hypoesthesia of the abdominal wall). ${ }^{7,8,18}$ Fewer than $2 \%$ of patients experience severe complications: hemorrhage requiring transfusion, cardiac or respiratory destabilization. ${ }^{7,8,18}$ However, cases of major complications have been reported outside of referral centers. ${ }^{20}$ Surgery should be performed by an experienced surgeon at an institution with a high volume of such interventions. In such settings, outpatient laparoscopic adrenalectomy is possible in selected cases: patients under the age of 65 years, tumors of less than $6 \mathrm{~cm}$ in diameter, no significant cardiorespiratory disease, first case of the day to be managed in the surgical program, residence less than 30 minutes from the hospital by car, and treatment with no more than three antihypertensive agents. ${ }^{21-23}$ 
Patients should be treated with a MRA and potassium supplements to lower BP and to correct hypokalemia before surgery. Preoperative mineralocorticoid receptor blockade for a few weeks before surgery may also decrease the risk of postoperative hypoaldosteronism due to the chronic suppression of aldosterone secretion in the contralateral gland. Nonetheless, postoperative hyperkalemia is seen in up to $30 \%$ of patients. ${ }^{24,25}$ It is usually mild and transient, but MRA treatment and potassium supplements should be discontinued at the time of surgery, to minimize the risk, and serum potassium concentrations should be monitored closely, particularly in patients with chronic kidney disease (CKD). ${ }^{25}$ In addition to the restriction of potassium-rich food, fludrocortisone has been used in rare cases of persistent hyperkalemia due to postoperative hypoaldosteronism. ${ }^{24}$ Hormonal studies should be carried out for patients with high BP after surgery, to distinguish between persistent PA and associated essential hypertension.

\section{Outcomes of adrenalectomy in unilateral PA}

We discuss here the findings of a systematic review of large surgical series published since $2000 .^{11}$ This time limit was set to correspond to current outcomes of laparoscopic surgery in patients with unilateral PA diagnosed with current protocols. This evidence base is nonetheless limited by the lack of comparison with drug-based treatment and medium-term evaluations of mostly intermediate outcomes (BP, serum potassium, subclinical target organ damage).

By definition, unilateral adrenalectomy should normalize aldosterone secretion in all cases of unilateral PA. However, 5 to $10 \%$ of patients display residual autonomous aldosterone production after surgery, even if hypertension is cured ${ }^{26}$ and adrenal venous sampling (AVS) is used in the diagnostic process. Hypokalemia, when present, resolves in more than $95 \%$ of 
cases, in all series. The mean rate of hypertension cure is $40 \%$, with a high variability between series. Patients with persistent hypertension nonetheless experience a clinically significant decline in $\mathrm{BP}$ (of between 20 and $40 \mathrm{mmHg}$ for systolic BP) and a decrease in the number of antihypertensive drug classes used (one or two fewer). Less than $25 \%$ of patients experience no apparent BP benefit from surgery.

An increase in markers of oxidative stress is observed more frequently in patients with PA than in patients with essential hypertension, and the levels of these markers decrease significantly after adrenalectomy in patients with unilateral disease. ${ }^{27}$

Patients with PA have higher cardiovascular morbidity and greater subclinical organ damage than expected on the basis of their BP. ${ }^{28}$ Many studies have shown that left ventricular mass decreases and that aortic pulse wave velocity and carotid intima-media thickness improve after adrenalectomy. ${ }^{29-35}$ A prospective study compared cardiovascular events in 54 PA patients treated by adrenalectomy (unilateral disease) or with spironolactone (unilateral or bilateral disease) with 323 patients with essential hypertension. ${ }^{36}$ The composite endpoint was myocardial infarction, stroke, any type of revascularization procedure, and sustained arrhythmia. Its incidence over a mean follow-up of 7.4 years did not differ between patients with treated PA and their controls (who achieved similar BP levels throughout follow-up). A study with a similar design found the incidence of cardiovascular events - acute coronary events, stroke, sustained arrhythmia, hospitalization for heart failure — to be slightly higher in 270 PA patients after specific treatment than in 810 matched patients with essential hypertension over a median follow-up period of 12 years. ${ }^{37}$ These discrepancies may be due to the higher rate of incident hospitalization for heart failure in PA patients than in controls in the second study, this outcome not being considered in the first study. 
A worsening of kidney function after adrenalectomy was first reported one year after Jerome Conn described the first APA. ${ }^{38}$ By contrast to otherwise similar patients with essential hypertension, patients with PA display relative glomerular hyperfiltration, defined as a high estimated glomerular filtration rate (eGFR) and low-grade albuminuria. ${ }^{39}$ These changes are associated with lower intrarenal arterial resistance and higher rates of blood flow in the kidney. ${ }^{40}$ They are most marked in patients with unilateral $\mathrm{PA}^{41,42}$ and are reversed within one month of adrenalectomy (Figure 1). ${ }^{40,43-55}$ Hemodynamic stress and hyperaldosteronism per $s e$ lead to chronic structural damage in the long run. ${ }^{45,56}$

PA patients have been reported to display a certain level of insulin resistance, which may improve after adrenalectomy. ${ }^{57,58}$ However, PA patients have the same likelihood of clinically defined glucose and lipid metabolism disorders at diagnosis as similar patients with essential hypertension, and adrenalectomy does not improve their clinical metabolic profile. ${ }^{37,59,60}$

One study suggests that the subjective well being of patients with unilateral PA, which is lower at baseline than that of the general population, significantly improves after adrenalectomy. $^{61}$

\section{Drug-based treatment for PA}

As the deleterious consequences of hyperaldosteronism depend on salt loading, dietary salt reduction is a cornerstone of medical treatment. A strict low-salt diet as the sole intervention in patients with PA reduces BP, restores the nocturnal dip in BP and lessens hypokalemia. ${ }^{62-64}$ Moreover, dietary salt reduction greatly potentiates the effect of spironolactone. ${ }^{65}$ However, 
strict compliance with a low-salt diet is as difficult to achieve in PA patients as in other subjects.

Spironolactone is a potent, cheap but non-selective MRA. The usual daily dose of spironolactone required to achieve normokalemia and a significant decrease in BP in patients with PA ranges from $50 \mathrm{mg}$ to $200 \mathrm{mg}$, and the published evidence was obtained from studies involving daily doses of $100 \mathrm{mg}$ or more. ${ }^{66}$ However, adverse effects of this drug, due to its anti-androgenic and anti-progesterone activity, limit the use of such doses in many men and some women. Doses below $50 \mathrm{mg} /$ day are usually well tolerated, ${ }^{67}$ but are not always sufficient to correct PA completely. Eplerenone, a selective MRA, is an appealing alternative in settings where its use for PA is approved. ${ }^{68}$ However, double the dose is required to achieve an efficacy similar to that of spironolactone for lowering BP, and the ceiling effect appears to occur sooner: a $10 \mathrm{mmHg}$ decreased in systolic BP at most, versus $25 \mathrm{mmHg}$ for spironolactone. ${ }^{69}$ Moreover, eplerenone must be administered twice daily to ensure activity throughout the day and is currently more expensive than spironolactone.

Amiloride is an ENaC blocker that opposes the reabsorption of sodium in exchange for potassium in the distal tubules and collecting ducts. In most countries, it is available in the form of $5 \mathrm{mg}$ tablets, although the usual daily dose required to correct hyperaldosteronism effectively is 10 to $40 \mathrm{mg} .{ }^{70}$ Its half life is 8 hours, and twice-daily intake is therefore required for an optimal effect. Triamterene is another ENaC blocker. ${ }^{71,72}$ In many countries, triamterene is only available in combination with thiazide diuretics. Amiloride (or triamterene) can be used to complement the highest well tolerated dose of spironolactone: as a rule of thumb, $10 \mathrm{mg}$ amiloride or $100 \mathrm{mg}$ triamterene prevent potassium wastage as effectively as $25 \mathrm{mg}$ spironolactone..$^{70,72}$ 
The long-term use of potassium supplements is undesirable. They are costly and cause gastrointestinal discomfort. Slow-release tablets are better tolerated but may cause esophageal and gastrointestinal ulcerations. Appropriate doses of spironolactone or amiloride are always sufficient to correct hypokalemia. Serum potassium concentration should be monitored 7 to 15 days after each change in the dose of potassium-sparing diuretics (MRAs, ENaC blockers).

MRAs, even if used in combination with ENaC blockers, are often insufficient to control BP. The most logical adjunctive treatments are thiazide diuretics and calcium channel blockers (CCB). Thiazide diuretics potentiate natriuresis, helping to decrease plasma volume. They act in synergy with spironolactone and ENaC blockers. ${ }^{65,71}$ In patients with low eGFR, they can be replaced by loop diuretics. Several dihydropyrine calcium channel antagonists weakly antagonize the mineralocorticoid receptor or inhibit key enzymes of aldosterone biosynthesis (most notably CYP1B2). ${ }^{73,74}$ Nifedipine, nitrendipine and felodipine are the available molecules with the greatest antialdosterone potency. Nifedipine has been tested as a monotherapy in 10 PA patients, and was shown to have a significant effect on BP, serum potassium and aldosterone concentrations at four weeks. ${ }^{75}$ Beta-blockers, angiotensinconverting enzyme (ACE) inhibitors, angiotensin receptor blockers (ARBs) and aliskiren are probably not the best choices for decreasing BP in PA patients, because renin activity is chronically suppressed in these patients. ${ }^{76}$ However, ARBs may be beneficial in some patients with bilateral hyperplasia or angiotensin-responsive adenoma. ${ }^{77,78}$

Finerenone, a new non-steroidal and highly potent MRA, has been studied in patients with chronic heart failure and mild CKD; it seems to decrease BNP and albuminuria as efficiently as spironolactone. ${ }^{79,80}$ Aldosterone synthase inhibitors are currently in clinical development. 
For instance, LCI699 has been tested in patients with PA, with mixed results: aldosterone secretion was decreased, but this did not translate into a lowering of BP. Moreover, the drug induced a blunted glucocorticoid response to ACTH of uncertain clinical significance. ${ }^{81,82}$

\section{Outcomes of drug-based treatment}

No randomized study has compared the BP outcome of adrenalectomy with that of specific drugs in patients with unilateral PA. However, drug-based treatment in 24 patients with unilateral PA led to normokalemia in all patients and long-lasting BP decreases of a magnitude similar to that observed in surgical series. ${ }^{83}$ Moreover, a prospective study showed that the BP-lowering effect of high-dose spironolactone was similar to, or even slightly greater than that of subsequent adrenalectomy in 44 patients. ${ }^{84}$

Spironolactone may appear to be less potent than adrenalectomy for improving left ventricular hypertrophy, but studies with long-term follow-up have shown that the same improvement is ultimately achieved, even though the regression of left ventricular mass is slower with spironolactone than with adrenalectomy. ${ }^{29,34,85}$ The benefits of PA treatment were similar for specific drugs and surgery in both studies comparing the incidence of cardiovascular events in treated PA patients and matched controls with essential hypertension. ${ }^{36,37}$

The relative glomerular hyperfiltration and microalbuminuria of PA patients are corrected on specific drugs (Figure 1). ${ }^{40,44-46,50,51,53-55}$ Spironolactone was found to be less effective than surgery for achieving this end in one study using a fixed low dose $(50 \mathrm{mg} /$ day $) .{ }^{50}$ Five other studies, with spironolactone uptitrated as needed and tolerated, revealed effects no different from those of surgery. ${ }^{44-46,48,53,55}$ 
PA patients treated with spironolactone or amiloride experience an improvement in wellbeing similar to that observed after adrenalectomy, although these effects appear to be established more slowly. ${ }^{86}$

\section{Treatment choice as a function of PA subtype}

Adrenal carcinomas are very rare (1-2/million subjects/year) and present as isolated PA in less than 5\% of cases. Carcinomas are often irregular and exceed $40 \mathrm{~mm}$ in size; their spontaneous density on adrenal $\mathrm{CT}$ is $>10 \mathrm{UH}$, with heterogeneous enhancement and slow contrast washout, and they may infiltrate surrounding tissues and invade adjacent organs. ${ }^{87}$ Resection by open surgery is the cornerstone of treatment, except for carcinomas with distant metastases.

Familial hyperaldosteronism type 1 or glucocorticoid-remediable aldosteronism (GRA) is also very rare. Patients with this disorder have a chimeric gene, placing aldosterone synthase transcription under the control of ACTH, causing bilateral PA. Autosomal dominant inheritance results in familial clusters of cases. Low-dose dexamethasone ( 0.125 to 0.25 $\mathrm{mg}$ /day) or low-dose prednisone (2.5 to $5 \mathrm{mg} /$ day) at bedtime efficiently suppresses ACTH secretion, thereby decreasing the ACTH-dependent hyperaldosteronism. ${ }^{88}$ The following characteristics of patients should lead to genetic testing: early primary aldosteronism $(<30$ years old) or early cerebrovascular events $(<50$ years old $)$, in the patient or a close relative. ${ }^{89}$

For the more common causes of PA, treatment options depend on lateralization: unilateral PA is amenable to adrenalectomy, whereas bilateral PA generally is not. Adrenal venous sampling (AVS) is recommended to compare the aldosterone secretion of the two adrenal glands. ${ }^{88,90,91}$ AVS is invasive, performed only at referral centers and its use is based on a 
pathophysiological rationale rather than solid clinical evidence. ${ }^{42,92}$ However, the rate of complications is low and no better supported alternative has yet been identified. ${ }^{93}$ Guidelines have recently been published, with the aim of decreasing the heterogeneity of AVS protocols and interpretation criteria, although the evidence supporting the recommendations is weak. ${ }^{94}$

Subtype diagnosis, and hence AVS, is required only if surgery is being considered. Some factors are significantly associated with persistent hypertension after surgery: ${ }^{11}$ being male, advanced age, familial hypertension, longer duration and higher grade of hypertension, higher body mass index, higher serum potassium concentration, lower glomerular filtration rate, higher $24 \mathrm{~h}$ urinary aldosterone secretion, subclinical target organ damage. However, none of these predictors has been consistently confirmed in all published series. Moreover, their predictive value at the individual level is limited. Typically, a patient with an unfavorable profile still has a $25 \%$ chance of being cured of hypertension by adrenalectomy ${ }^{95}$ and, even if hypertension persists, the patient will experience a significant decrease in BP and/or treatment requirements. ${ }^{92}$ Moreover, the normalization of aldosterone secretion probably has BPindependent benefits. Factors predictive of the persistence of hypertension after adrenalectomy should not, therefore, be used as arguments for or against surgery in individual cases.

Surgery should be considered an option in all patients without contraindication who are willing to undergo AVS, followed by adrenalectomy if lateralization is demonstrated. Unlike the drugs currently available, surgery normalizes aldosterone secretion, thereby preventing all the effects of aldosterone overproduction. However, as we have seen above, this theoretical advantage does not translate into a proven clinical advantage over specific drug treatment. 
The most consistent argument for surgery in unilateral PA is that it eliminates or decreases the need for drug treatment and the economic and psychological burden that such drug treatment entails. A primitive cost-effectiveness analysis found that adrenalectomy, with a $35 \%$ cure rate and a $85 \%$ improvement rate, was a cost-saving option for 50-year-old PA patients, as it eliminated the need for lifelong drug therapy. ${ }^{96}$ Another more thorough cost-effectiveness analysis suggested that, for PA patients with a life expectancy of more than 25 years, performing AVS in all patients and adrenalectomy in those displaying lateralization would be cheaper than not carrying out AVS and providing lifelong drug treatment for all patients. ${ }^{97}$ However, the assumptions of the model (cure rate; cost of medical treatment, AVS and surgery) may not extend to all settings.

Younger patients have a longer life expectancy and therefore derive greater benefit from surgery. The risk of anesthesia is also smallest in this group of patients. The early diagnosis of unilateral PA is therefore important. Patients with resistant hypertension may also derive a significant benefit from surgery, particularly if compliance is an issue or if spironolactone is ineffective or not well tolerated. The benefit-risk ratio is less positive in older patients, particularly if there are compelling indications for antihypertensive drugs, which must be continued irrespective of BP levels. This is the case for beta-blockers for coronary artery disease and for ACE inhibitors and spironolactone for heart failure.

Only the few patients at high surgical risk and those with a short life expectancy should be advised against surgery. However, patients should not be coerced into considering surgery if they prefer not to undergo the procedure, given that there is reasonable evidence to suggest that lifelong treatment with mineralocorticoid antagonists is a valid alternative to surgery. Treatment choice should therefore also be driven by the preferences of the patient. Candidates 
for surgery should be told that the presence of an APA poses no risk in terms of cancer. They should also be informed that the clinical outcomes of surgery and medication are similar, that hypertension is cured by surgery in only $40 \%$ of cases but that medication levels and BP are lowered even in those not cured, and that, in the absence of surgery, medication is lifelong and not always well tolerated. Patients may opt for a trial period on spironolactone before deciding whether to consider surgery and, therefore, to undergo AVS.

Patients with bilateral PA and those who refuse or have a contraindication for surgery should be treated with spironolactone, beginning with a dose of $25 \mathrm{mg} /$ day, with uptitration until kalemia and blood pressure are normalized. Dietary sodium restriction should be actively promoted, because the deleterious consequences of hyperaldosteronism depend on salt loading. If spironolactone is poorly tolerated, the highest accepted dose should be complemented with amiloride, starting at a dose of $5 \mathrm{mg}$ twice daily, with uptitration as required. Eplerenone can be used instead of this spironolactone-amiloride combination in settings in which it is approved for the treatment of hypertension, provided that the patient can afford it. We favor the spironolactone-amiloride combination over eplerenone because a beneficial impact on clinical events has been shown with spironolactone but not yet with eplerenone. If BP remains uncontrolled despite potassium-sparing diuretics, thiazide or loop diuretics and CCB should be added, as required. Unilateral adrenalectomy has been performed in a few patients with presumed bilateral disease refractory to drug treatment or unable to tolerate optimal medical management. ${ }^{98}$ Hypertension was cured or improved in about one third of these patients, particularly those with mild PA or one dominant adrenal gland on AVS, even though the lateralization criterion was not met. 
CKD affects the clinical profile of patients with PA and the effectiveness and risk associated with treatment options; it must therefore be taken into account when clinical decisions are made (Table 1). 


\section{References}

1. Amar L, Plouin P-F, Steichen O. Aldosterone-producing adenoma and other surgically correctable forms of primary aldosteronism. Orphanet J Rare Dis 2010;5:9. doi:10.1186/1750-1172-5-9.

2. Hoorn EJ, Nelson JH, McCormick JA, Ellison DH. The WNK kinase network regulating sodium, potassium, and blood pressure. J. Am. Soc. Nephrol. 2011;22(4):605-614. doi:10.1681/ASN.2010080827.

3. McCurley A, Pires PW, Bender SB, et al. Direct regulation of blood pressure by smooth muscle cell mineralocorticoid receptors. Nat Med 2012;18(9):1429-1433. doi:10.1038/nm.2891.

4. Pimenta E, Gordon RD, Ahmed AH, et al. Cardiac dimensions are largely determined by dietary salt in patients with primary aldosteronism: results of a case-control study. J Clin Endocrinol Metab 2011;96(9):2813-2820. doi:10.1210/jc.2011-0354.

5. Pimenta E, Gordon RD, Stowasser M. Salt, aldosterone and hypertension. J Hum Hypertens 2013;27(1):1-6. doi:10.1038/jhh.2012.27.

6. Catena C, Colussi G, Sechi LA. Aldosterone, organ damage and dietary salt. Clin Exp Pharmacol Physiol 2013;40(12):922-928. doi:10.1111/1440-1681.12145.

7. Assalia A, Gagner M. Laparoscopic adrenalectomy. Br J Surg 2004;91(10):1259-1274. doi:10.1002/bjs.4738.

8. Brunt LM. Minimal access adrenal surgery. Surg Endosc 2006;20(3):351-361. doi:10.1007/s00464-004-8269-3.

9. Kaye DR, Storey BB, Pacak K, Pinto PA, Linehan WM, Bratslavsky G. Partial adrenalectomy: underused first line therapy for small adrenal tumors. $J$ Urol 2010;184(1):18-25. doi:10.1016/j.juro.2010.03.052.

10. Fu B, Zhang X, Wang G, et al. Long-term results of a prospective, randomized trial comparing retroperitoneoscopic partial versus total adrenalectomy for aldosterone producing adenoma. J Urol 2011;185(5):1578-1582. doi:10.1016/j.juro.2010.12.051.

11. Steichen O, Zinzindohoué F, Plouin P-F, Amar L. Outcomes of adrenalectomy in patients with unilateral primary aldosteronism: a review. Horm Metab Res 2012;44(3):221-227. doi:10.1055/s-0031-1299681.

12. Nunes TF, Szejnfeld D, Xavier ACW, et al. Percutaneous ablation of functioning adrenal adenoma: a report on 11 cases and a review of the literature. Abdom Imaging 2013;38(5):1130-1135. doi:10.1007/s00261-013-9995-6. 
13. Constantinides VA, Christakis I, Touska P, Palazzo FF. Systematic review and metaanalysis of retroperitoneoscopic versus laparoscopic adrenalectomy. Br J Surg 2012;99(12):1639-1648. doi:10.1002/bjs.8921.

14. Yuge K, Miyajima A, Hasegawa M, et al. Initial experience of transumbilical laparoendoscopic single-site surgery of partial adrenalectomy in patient with aldosterone-producing adenoma. BMC Urol 2010;10:19. doi:10.1186/1471-2490-10-19.

15. Merseburger AS, Herrmann TRW, Shariat SF, et al. EAU guidelines on robotic and single-site surgery in urology. Eur Urol 2013;64(2):277-291. doi:10.1016/j.eururo.2013.05.034.

16. Hyams ES, Stifelman MD. The role of robotics for adrenal pathology. Curr Opin Urol 2009;19(1):89-96. doi:10.1097/MOU.0b013e32831b446c.

17. Brandao LF, Autorino R, Laydner H, et al. Robotic versus laparoscopic adrenalectomy: a systematic review and meta-analysis. Eur Urol 2014;65(6):1154-1161. doi:10.1016/j.eururo.2013.09.021.

18. Walz MK, Alesina PF, Wenger FA, et al. Posterior retroperitoneoscopic adrenalectomy-results of 560 procedures in 520 patients. Surgery 2006;140(6):943-948; discussion 948950. doi:10.1016/j.surg.2006.07.039.

19. O’Boyle CJ, Kapadia CR, Sedman PC, Brough WA, Royston CMS. Laparoscopic transperitoneal adrenalectomy. Surg Endosc 2003;17(12):1905-1909. doi:10.1007/s00464-002-8878-7.

20. Tessier DJ, Iglesias R, Chapman WC, et al. Previously unreported high-grade complications of adrenalectomy. Surg Endosc 2009;23(1):97-102. doi:10.1007/s00464008-9947-3.

21. Gill IS, Hobart MG, Schweizer D, Bravo EL. Outpatient adrenalectomy. J Urol 2000;163(3):717-720.

22. Edwin B, Raeder I, Trondsen E, Kaaresen R, Buanes T. Outpatient laparoscopic adrenalectomy in patients with Conn's syndrome. Surg Endosc 2001;15(6):589-591. doi:10.1007/s004640090021.

23. Ramírez-Plaza CP, Perales JLG, Camero NM, Rodríguez-Cañete A, Bondía-Navarro JA, Santoyo-Santoyo J. Outpatient laparoscopic adrenalectomy: a new step ahead. Surg Endosc 2011;25(8):2570-2573. doi:10.1007/s00464-011-1588-2.

24. Fischer E, Hanslik G, Pallauf A, et al. Prolonged zona glomerulosa insufficiency causing hyperkalemia in primary aldosteronism after adrenalectomy. J Clin Endocrinol Metab 2012;97(11):3965-3973. doi:10.1210/jc.2012-2234.

25. Chiang W-F, Cheng C-J, Wu S-T, et al. Incidence and factors of post-adrenalectomy hyperkalemia in patients with aldosterone producing adenoma. Clin Chim Acta 2013;424:114-118. doi:10.1016/j.cca.2013.05.017. 
26. Rutherford JC, Taylor WL, Stowasser M, Gordon RD. Success of surgery for primary aldosteronism judged by residual autonomous aldosterone production. World J Surg 1998;22(12):1243-1245.

27. Petramala L, Pignatelli $\mathrm{P}$, Carnevale R, et al. Oxidative stress in patients affected by primary aldosteronism. J Hypertens 2014;32(10):2022-2029. doi:10.1097/HJH.0000000000000284.

28. Savard S, Amar L, Plouin P-F, Steichen O. Cardiovascular complications associated with primary aldosteronism: a controlled cross-sectional study. Hypertension 2013;62(2):331-336. doi:10.1161/HYPERTENSIONAHA.113.01060.

29. Catena C, Colussi G, Lapenna R, et al. Long-term cardiac effects of adrenalectomy or mineralocorticoid antagonists in patients with primary aldosteronism. Hypertension 2007;50(5):911-918. doi:10.1161/HYPERTENSIONAHA.107.095448.

30. Gaddam K, Corros C, Pimenta E, et al. Rapid reversal of left ventricular hypertrophy and intracardiac volume overload in patients with resistant hypertension and hyperaldosteronism: a prospective clinical study. Hypertension 2010;55(5):1137-1142. doi:10.1161/HYPERTENSIONAHA.109.141531.

31. Lin Y-H, Huang K-H, Lee J-K, et al. Factors influencing left ventricular mass regression in patients with primary aldosteronism post adrenalectomy. J Renin Angiotensin Aldosterone Syst 2011;12(1):48-53. doi:10.1177/1470320310376424.

32. Lin $\mathrm{Y}-\mathrm{H}, \mathrm{Wu} \mathrm{X}-\mathrm{M}$, Lee $\mathrm{H}-\mathrm{H}$, et al. Adrenalectomy reverses myocardial fibrosis in patients with primary aldosteronism. J Hypertens 2012;30(8):1606-1613. doi:10.1097/HJH.0b013e3283550f93.

33. Lin Y-H, Lin L-Y, Chen A, et al. Adrenalectomy improves increased carotid intimamedia thickness and arterial stiffness in patients with aldosterone producing adenoma. Atherosclerosis 2012;221(1):154-159. doi:10.1016/j.atherosclerosis.2011.12.003.

34. Rossi GP, Cesari M, Cuspidi C, et al. Long-term control of arterial hypertension and regression of left ventricular hypertrophy with treatment of primary aldosteronism. Hypertension 2013;62(1):62-69. doi:10.1161/HYPERTENSIONAHA.113.01316.

35. Strauch B, Petrák O, Zelinka T, et al. Adrenalectomy improves arterial stiffness in primary aldosteronism. Am J Hypertens 2008;21(10):1086-1092. doi:10.1038/ajh.2008.243.

36. Catena C, Colussi G, Nadalini E, et al. Cardiovascular outcomes in patients with primary aldosteronism after treatment. Arch Intern Med 2008;168(1):80-85. doi:10.1001/archinternmed.2007.33.

37. Mulatero P, Monticone S, Bertello C, et al. Long-term cardio- and cerebrovascular events in patients with primary aldosteronism. J Clin Endocrinol Metab 2013;98(12):4826-4833. doi:10.1210/jc.2013-2805.

38. Dustan HP, Corcoran AC, Page IH. Renal function in primary aldosteronism. J Clin Invest 1956;35(12):1357-1363. 
39. Kuo C-C, Wu V-C, Tsai C-W, Wu K-D, Taiwan Primary Aldosteronism Investigation (TAIPAI) Study Group). Relative kidney hyperfiltration in primary aldosteronism: a meta-analysis. J Renin Angiotensin Aldosterone Syst 2011;12(2):113-122. doi:10.1177/1470320310391331.

40. Sechi LA, Di Fabio A, Bazzocchi M, Uzzau A, Catena C. Intrarenal hemodynamics in primary aldosteronism before and after treatment. J Clin Endocrinol Metab 2009;94(4):1191-1197. doi:10.1210/jc.2008-2245.

41. Rossi GP, Bernini G, Desideri G, et al. Renal damage in primary aldosteronism: results of the PAPY Study. Hypertension 2006;48(2):232-238. doi:10.1161/01.HYP.0000230444.01215.6a.

42. Küpers EM, Amar L, Raynaud A, Plouin P-F, Steichen O. A clinical prediction score to diagnose unilateral primary aldosteronism. J Clin Endocrinol Metab 2012;97(10):35303537. doi:10.1210/jc.2012-1917.

43. Ribstein J, Du Cailar G, Fesler P, Mimran A. Relative glomerular hyperfiltration in primary aldosteronism. J Am Soc Nephrol 2005;16(5):1320-1325. doi:10.1681/ASN.2004100878.

44. Sechi LA, Novello M, Lapenna R, et al. Long-term renal outcomes in patients with primary aldosteronism. JAMA 2006;295(22):2638-2645. doi:10.1001/jama.295.22.2638.

45. Catena C, Colussi G, Nadalini E, et al. Relationships of plasma renin levels with renal function in patients with primary aldosteronism. Clin J Am Soc Nephrol 2007;2(4):722731. doi:10.2215/CJN.00050107.

46. Reincke M, Rump LC, Quinkler M, et al. Risk factors associated with a low glomerular filtration rate in primary aldosteronism. J Clin Endocrinol Metab 2009;94(3):869-875. doi:10.1210/jc.2008-1851.

47. Takahashi K, Fujita T. What is the clinical significance of masked chronic kidney disease in patients with primary aldosteronism? Endocr J 2010;57:S639.

48. Tsuiki M, Tanabe A, Naruse M, et al. Renal function deteriorates regardless of the type of treatments in primary aldosteronism. Endocr J 2010;57:S646.

49. Pimenta E, Gordon RD, Ahmed AH, et al. Unilateral adrenalectomy improves urinary protein excretion but does not abolish its relationship to sodium excretion in patients with aldosterone-producing adenoma. J Hum Hypertens 2011;25(10):592-599. doi:10.1038/jhh.2010.102.

50. Wu V-C, Kuo C-C, Wang S-M, et al. Primary aldosteronism: changes in cystatin Cbased kidney filtration, proteinuria, and renal duplex indices with treatment. J Hypertens 2011;29(9):1778-1786. doi:10.1097/HJH.0b013e3283495cbb.

51. Wu V-C, Yang S-Y, Lin J-W, et al. Kidney impairment in primary aldosteronism. Clin Chim Acta 2011;412(15-16):1319-1325. doi:10.1016/j.cca.2011.02.018.

52. Utsumi T, Kawamura K, Imamoto T, et al. Preoperative masked renal damage in Japanese patients with primary aldosteronism: identification of predictors for chronic 
kidney disease manifested after adrenalectomy. Int J Urol 2013;20(7):685-691. doi:10.1111/iju.12029.

53. Fourkiotis V, Vonend O, Diederich S, et al. Effectiveness of eplerenone or spironolactone treatment in preserving renal function in primary aldosteronism. Eur $J$ Endocrinol 2013;168(1):75-81. doi:10.1530/EJE-12-0631.

54. Tanase-Nakao K, Naruse M, Nanba K, et al. Chronic kidney disease score for predicting postoperative masked renal insufficiency in patients with primary aldosteronism. Clin Endocrinol (Oxf) 2014. doi:10.1111/cen.12497.

55. Iwakura Y, Morimoto R, Kudo M, et al. Predictors of decreasing glomerular filtration rate and prevalence of chronic kidney disease after treatment of primary aldosteronism: renal outcome of 213 cases. J Clin Endocrinol Metab 2014;99(5):1593-1598. doi:10.1210/jc.2013-2180.

56. Brem AS, Morris DJ, Gong R. Aldosterone-induced fibrosis in the kidney: questions and controversies. Am J Kidney Dis 2011;58(3):471-479. doi:10.1053/j.ajkd.2011.03.029.

57. Catena $\mathrm{C}$, Lapenna $\mathrm{R}$, Baroselli $\mathrm{S}$, et al. Insulin sensitivity in patients with primary aldosteronism: a follow-up study. J Clin Endocrinol Metab 2006;91(9):3457-3463. doi:10.1210/jc.2006-0736.

58. Giacchetti G, Ronconi V, Turchi F, et al. Aldosterone as a key mediator of the cardiometabolic syndrome in primary aldosteronism: an observational study. $J$ Hypertens 2007;25(1):177-186. doi:10.1097/HJH.0b013e3280108e6f.

59. Matrozova J, Steichen O, Amar L, Zacharieva S, Jeunemaitre X, Plouin P-F. Fasting plasma glucose and serum lipids in patients with primary aldosteronism: a controlled cross-sectional study. Hypertension 2009;53(4):605-610. doi:10.1161/HYPERTENSIONAHA.108.122002.

60. Somlóová Z, Widimský J, Rosa J, et al. The prevalence of metabolic syndrome and its components in two main types of primary aldosteronism. J Hum Hypertens 2010;24(10):625-630. doi:10.1038/jhh.2010.65.

61. Sukor N, Kogovsek C, Gordon RD, Robson D, Stowasser M. Improved quality of life, blood pressure, and biochemical status following laparoscopic adrenalectomy for unilateral primary aldosteronism. J Clin Endocrinol Metab 2010;95(3):1360-1364. doi:10.1210/jc.2009-1763.

62. Pedrinelli R, Bruschi G, Graziadei L, et al. Dietary sodium change in primary aldosteronism. Atrial natriuretic factor, hormonal, and vascular responses. Hypertension 1988;12(2):192-198.

63. Uzu T, Nishimura M, Fujii T, et al. Changes in the circadian rhythm of blood pressure in primary aldosteronism in response to dietary sodium restriction and adrenalectomy. $J$ Hypertens 1998;16(12 Pt 1):1745-1748.

64. Takakuwa H, Shimizu K, Izumiya Y, et al. Dietary sodium restriction restores nocturnal reduction of blood pressure in patients with primary aldosteronism. Hypertens Res 2002;25(5):737-742. 
65. Bravo EL, Dustan HP, Tarazi RC. Spironolactone as a nonspecific treatment for primary aldosteronism. Circulation 1973;48(3):491-498.

66. Lim PO, Young WF, MacDonald TM. A review of the medical treatment of primary aldosteronism. J Hypertens 2001;19(3):353-361.

67. Jeunemaitre X, Chatellier G, Kreft-Jais C, et al. Efficacy and tolerance of spironolactone in essential hypertension. Am J Cardiol 1987;60(10):820-825.

68. Karagiannis A, Tziomalos K, Papageorgiou A, et al. Spironolactone versus eplerenone for the treatment of idiopathic hyperaldosteronism. Expert Opin Pharmacother 2008;9(4):509-515. doi:10.1517/14656566.9.4.509.

69. Parthasarathy HK, Ménard J, White WB, et al. A double-blind, randomized study comparing the antihypertensive effect of eplerenone and spironolactone in patients with hypertension and evidence of primary aldosteronism. J Hypertens 2011;29(5):980-990. doi:10.1097/HJH.0b013e3283455ca5.

70. Ramsay LE, Hettiarachchi J, Fraser R, Morton JJ. Amiloride, spironolactone, and potassium chloride in thiazide-treated hypertensive patients. Clin Pharmacol Ther 1980;27(4):533-543.

71. Ganguly A, Weinberger MH. Triamterene-thiazide combination: alternative therapy for primary aldosteronism. Clin Pharmacol Ther 1981;30(2):246-250.

72. Jackson PR, Ramsay LE, Wakefield V. Relative potency of spironolactone, triamterene and potassium chloride in thiazide-induced hypokalaemia. Br J Clin Pharmacol 1982;14(2):257-263.

73. Dietz JD, Du S, Bolten CW, et al. A number of marketed dihydropyridine calcium channel blockers have mineralocorticoid receptor antagonist activity. Hypertension 2008;51(3):742-748. doi:10.1161/HYPERTENSIONAHA.107.103580.

74. Ikeda K, Isaka T, Fujioka K, Manome Y, Tojo K. Suppression of aldosterone synthesis and secretion by $\mathrm{Ca}(2+)$ channel antagonists. Int J Endocrinol 2012;2012:519467. doi:10.1155/2012/519467.

75. Nadler JL, Hsueh W, Horton R. Therapeutic effect of calcium channel blockade in primary aldosteronism. J Clin Endocrinol Metab 1985;60(5):896-899. doi:10.1210/jcem60-5-896.

76. Bubbar CD, Blackburn DF, Wilson MP, Wilson TW. Angiotensin-converting enzyme inhibitors and angiotensin receptor blockers in hypertension due to primary aldosteronism: a case for exclusion. Ann Pharmacother 2007;41(1):129-132. doi:10.1345/aph.1H456.

77. Gordon RD, Hamlet SM, Tunny TJ, Klemm SA. Aldosterone-producing adenomas responsive to angiotensin pose problems in diagnosis. Clin. Exp. Pharmacol. Physiol. 1987;14(3):175-179. 
78. Zacharieva S, Atanassova I, Natchev E, Orbetzova M, Tzingilev D. Effect of short-term losartan treatment in patients with primary aldosteronism and essential hypertension. Methods Find Exp Clin Pharmacol 2001;23(3):153-156.

79. Pitt B, Kober L, Ponikowski P, et al. Safety and tolerability of the novel non-steroidal mineralocorticoid receptor antagonist BAY 94-8862 in patients with chronic heart failure and mild or moderate chronic kidney disease: a randomized, double-blind trial. Eur Heart J 2013;34(31):2453-2463. doi:10.1093/eurheartj/eht187.

80. Kolkhof P, Delbeck M, Kretschmer A, et al. Finerenone, a novel selective nonsteroidal mineralocorticoid receptor antagonist protects from rat cardiorenal injury. J. Cardiovasc. Pharmacol. 2014;64(1):69-78. doi:10.1097/FJC.0000000000000091.

81. Amar L, Azizi M, Menard J, Peyrard S, Watson C, Plouin P-F. Aldosterone synthase inhibition with LCI699: a proof-of-concept study in patients with primary aldosteronism. Hypertension 2010;56(5):831-838. doi:10.1161/HYPERTENSIONAHA.110.157271.

82. Amar L, Azizi M, Menard J, Peyrard S, Plouin P-F. Sequential comparison of aldosterone synthase inhibition and mineralocorticoid blockade in patients with primary aldosteronism. J Hypertens 2013;31(3):624-629; discussion 629. doi:10.1097/HJH.0b013e32835d6d49.

83. Ghose RP, Hall PM, Bravo EL. Medical management of aldosterone-producing adenomas. Ann Intern Med 1999;131(2):105-108.

84. Ferriss JB, Beevers DG, Boddy K, et al. The treatment of low-renin ("primary") hyperaldosteronism. Am Heart J 1978;96(1):97-109.

85. Ori Y, Chagnac A, Korzets A, et al. Regression of left ventricular hypertrophy in patients with primary aldosteronism/low-renin hypertension on low-dose spironolactone. Nephrol Dial Transplant 2013;28(7):1787-1793. doi:10.1093/ndt/gfs587.

86. Ahmed AH, Gordon RD, Sukor N, Pimenta E, Stowasser M. Quality of life in patients with bilateral primary aldosteronism before and during treatment with spironolactone and/or amiloride, including a comparison with our previously published results in those with unilateral disease treated surgically. J Clin Endocrinol Metab 2011;96(9):29042911. doi:10.1210/jc.2011-0138.

87. $\mathrm{Ng}$ L, Libertino JM. Adrenocortical carcinoma: diagnosis, evaluation and treatment. $J$ Urol 2003;169(1):5-11. doi:10.1097/01.ju.0000030148.59051.35.

88. Funder JW, Carey RM, Fardella C, et al. Case detection, diagnosis, and treatment of patients with primary aldosteronism: an endocrine society clinical practice guideline. $J$ Clin Endocrinol Metab 2008;93(9):3266-3281. doi:10.1210/jc.2008-0104.

89. Litchfield WR, Anderson BF, Weiss RJ, Lifton RP, Dluhy RG. Intracranial aneurysm and hemorrhagic stroke in glucocorticoid-remediable aldosteronism. Hypertension 1998;31(1 Pt 2):445-450.

90. Zeiger MA, Thompson GB, Duh Q-Y, et al. The American Association of Clinical Endocrinologists and American Association of Endocrine Surgeons medical guidelines 
for the management of adrenal incidentalomas. Endocr Pract 2009;15 Suppl 1:1-20. doi:10.4158/EP.15.S1.1.

91. Nishikawa T, Omura M, Satoh F, et al. Guidelines for the diagnosis and treatment of primary aldosteronism--the Japan Endocrine Society 2009. Endocr J 2011;58(9):711721.

92. Van der Linden P, Steichen O, Zinzindohoué F, Plouin P-F. Blood pressure and medication changes following adrenalectomy for unilateral primary aldosteronism: a follow-up study. J Hypertens 2012;30(4):761-769. doi:10.1097/HJH.0b013e328350225d.

93. Rossi GP, Barisa M, Allolio B, et al. The Adrenal Vein Sampling International Study (AVIS) for identifying the major subtypes of primary aldosteronism. J Clin Endocrinol Metab 2012;97(5):1606-1614. doi:10.1210/jc.2011-2830.

94. Rossi GP, Auchus RJ, Brown M, et al. An expert consensus statement on use of adrenal vein sampling for the subtyping of primary aldosteronism. Hypertension 2014;63(1):151-160. doi:10.1161/HYPERTENSIONAHA.113.02097.

95. Zarnegar R, Young WF, Lee J, et al. The aldosteronoma resolution score: predicting complete resolution of hypertension after adrenalectomy for aldosteronoma. Ann Surg 2008;247(3):511-518. doi:10.1097/SLA.0b013e318165c075.

96. Sywak M, Pasieka JL. Long-term follow-up and cost benefit of adrenalectomy in patients with primary hyperaldosteronism. Br J Surg 2002;89(12):1587-1593. doi:10.1046/j.1365-2168.2002.02261.x.

97. Reimel B, Zanocco K, Russo MJ, et al. The management of aldosterone-producing adrenal adenomas--does adrenalectomy increase costs? Surgery 2010;148(6):1178-1185; discussion 1185. doi:10.1016/j.surg.2010.09.012.

98. Sukor N, Gordon RD, Ku YK, Jones M, Stowasser M. Role of unilateral adrenalectomy in bilateral primary aldosteronism: a 22-year single center experience. J. Clin.

Endocrinol. Metab. 2009;94(7):2437-2445. doi:10.1210/jc.2008-2803.

99. Burshteyn M, Cohen DL, Fraker DL, Trerotola SO. Adrenal venous sampling for primary hyperaldosteronism in patients with concurrent chronic kidney disease. $J$ Vasc Interv Radiol 2013;24(5):726-733. doi:10.1016/j.jvir.2013.01.496.

100. Kidney Disease Outcomes Quality Initiative (K/DOQI). K/DOQI clinical practice guidelines on hypertension and antihypertensive agents in chronic kidney disease. Am J Kidney Dis 2004;43(5 Suppl 1):S1-290.

101. Briet M, Schiffrin EL. Aldosterone: effects on the kidney and cardiovascular system. Nat Rev Nephrol 2010;6(5):261-273. doi:10.1038/nrneph.2010.30. 
Table 1. Particularities of primary aldosteronism (PA) treatment in patients with chronic

kidney disease (CKD)

\begin{tabular}{|c|c|}
\hline & \\
\hline & $\begin{array}{l}\text { Contrast nephropathy is a specific concern when planning to perform adrenal venous } \\
\text { sampling in CKD patients to identify those who could undergo adrenalectomy. } \\
\text { However, complications are rare with appropriate hydration and the smallest possible } \\
\text { amount of a low-osmolar contrast medium (less than } 50 \mathrm{ml}) .{ }^{99} \\
\text { Patients with CKD are at risk of hyperkalemia after adrenalectomy. Mineralocorticoid } \\
\text { receptor antagonist treatment and potassium supplements should be discontinued } \\
\text { immediately after surgery and serum potassium concentrations should be monitored } \\
\text { closely. } \\
\text { Adrenalectomy also unmasks postoperative eGFR below } 60 \mathrm{ml} / \mathrm{min} / 1.73 \mathrm{~m}^{2} \text { in } 30 \% \text { to } \\
40 \% \text { of patients with unilateral PA. }{ }^{52,54,55} \text { It is more likely in patients who have a } \\
\text { preoperative eGFR that is already close to this threshold. }\end{array}$ \\
\hline & -based treatment \\
\hline & $\begin{array}{l}\text { The pharmacokinetics of spironolactone and eplerenone are unaffected in patients with } \\
\text { CKD. }{ }^{100} \text { Amiloride is partly excreted in the urine and its half-life is longer in patients } \\
\text { with CKD, so lower doses and once-daily intakes can be used. Triamterene } \\
\text { crystallizes in the urine, causing nephrolithiasis and acute kidney injury. It should not } \\
\text { be used in patients with CKD. } \\
\text { Patients with CKD are prone to hyperkalemia with potassium-sparing diuretics } \\
\text { (mineralocorticoid receptor and epithelial sodium channel blockers). However, } \\
\text { patients with CKD are likely to require higher doses of mineralocorticoid blockers, } \\
\text { due to their antiproteinuric and antifibrosing effects. }{ }^{101} \text { The initiation of treatment at a } \\
\text { low dose and slow upward titration are advised. }{ }^{100} \text { Serum potassium concentration } \\
\text { should be monitored within } 7 \text { days of each change in the dose of potassium-sparing } \\
\text { diuretics. } \\
\text { Several drugs potentiate potassium retention and should be used with caution: beta- } \\
\text { blockers, angiotensin-converting enzyme inhibitors, angiotensin receptor blockers, } \\
\text { aliskiren, nonsteroidal anti-inflammatory drugs, heparins, trimethoprim, and } \\
\text { calcineurin inhibitors. Loop diuretics and low-potassium diet can help to control } \\
\text { hyperkalemia in patients with advanced CKD who are taking potassium-sparing } \\
\text { diuretics. } \\
\text { Finerenone, a new non-steroidal mineralocorticoid receptor antagonist seems to be as } \\
\text { effective as spironolactone and results in lower levels of hyperkalemia in patients with } \\
\text { mild CKD. }\end{array}$ \\
\hline
\end{tabular}


Figure 1. Kidney function decline after the specific treatment of primary aldosteronism

*standardized mean differences are expressed as the number of observed standard deviations 
Estimated glomerular filtration rate mean (standard deviation), $\mathrm{ml} / \mathrm{min} / 1.73 \mathrm{~m}^{2}$
Standardized mean difference* (95\% confidence interval)

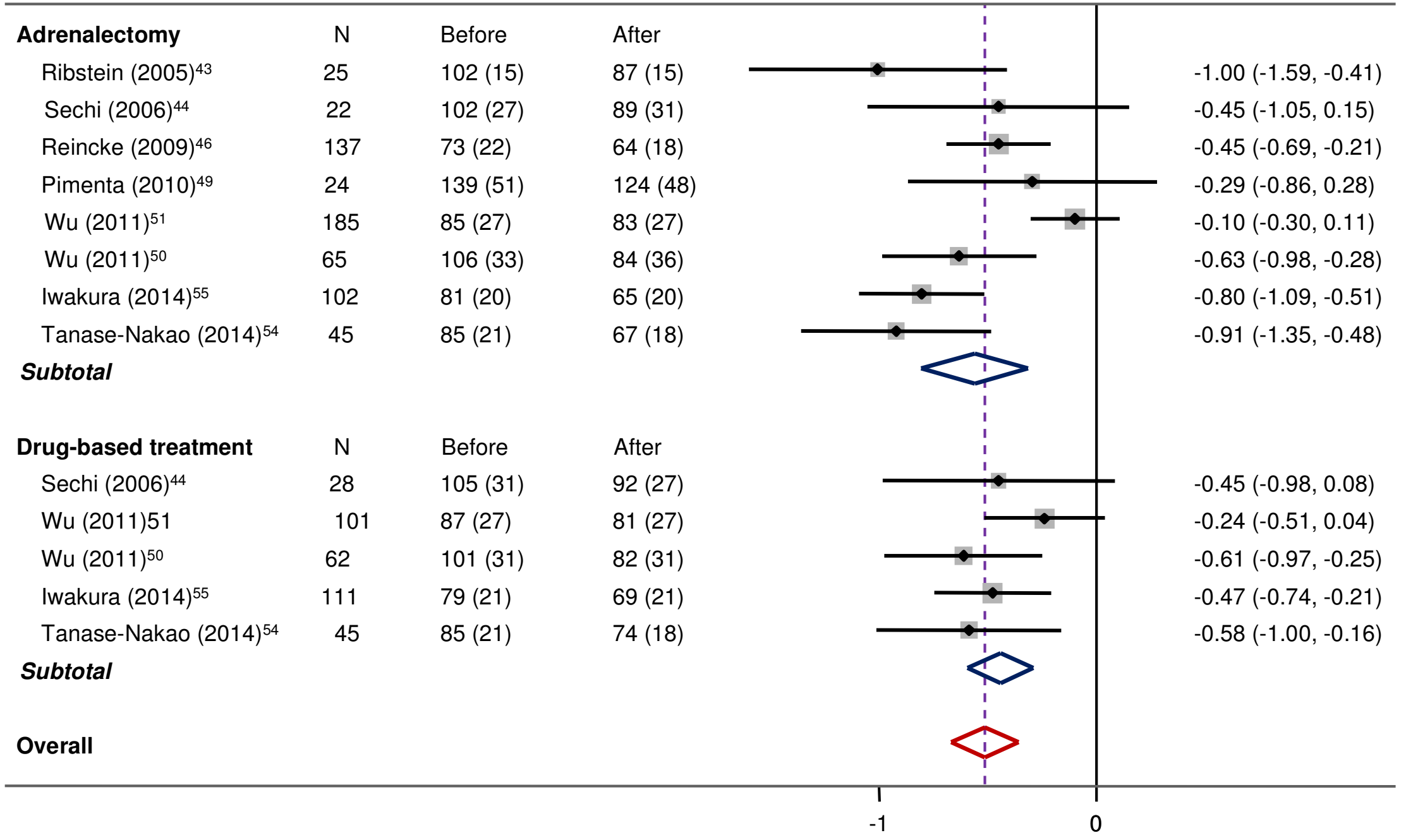

